\title{
User Roles and Contributions in User Innovation Community
}

\author{
Qian Yang1, Cheng Li ${ }^{2}$ \\ ${ }^{1}$ School of Management, Jinan University, Guangzhou, China \\ ${ }^{2}$ School of International Business, Jinan University, Zhuhai, China \\ Email: Jinanyanqian@163.com, lcqd@stu2018.jun.edu.cn
}

How to cite this paper: Yang, Q. and Li, C. (2019) User Roles and Contributions in User Innovation Community. American Journal of Industrial and Business Management, 9, 1318-1331.

https://doi.org/10.4236/ajibm.2019.96087

Received: May 25, 2019

Accepted: June 9, 2019

Published: June 12, 2019

Copyright (อ 2019 by author(s) and Scientific Research Publishing Inc. This work is licensed under the Creative Commons Attribution International License (CC BY 4.0).

http://creativecommons.org/licenses/by/4.0/ (c) (i) Open Access

\begin{abstract}
User innovation community is an important source for enterprises to obtain originality and relevant product information. In user innovation communities, users are the creators and participators of content and also the providers of wisdom. Classifying the type of users would help people play a more positive role in the open knowledge communities, and improve the innovation, sharing of knowledge and generation of wisdom more preferably. In order to help enterprises to successfully manage the community's users, HUAWEI cellphone community is taken as an example to explore different contributions of online users with district behavior characteristics. The user samples are classified by these four indicators to build a matrix classification model of users such as creation number, knowledge degree, in-degree centrality and out-degree centrality with $\mathrm{K}$-means clustering. And it further draws six different types of user roles, including core users, active contributors, passive contributors, social users, information acquiring users and divers. It also provides management strategies for enterprises to classify and manage different types of users when operating user innovation communities.
\end{abstract}

\section{Keywords}

User Innovation Community, User Role, User Contribution, K-Means Clustering

\section{Introduction}

Innovation is a critical activity for sustaining firms' competitiveness in the market [1]. As a result, firms continue to invest in the development of new products, services, and processes. However, managers are concerned about how to encourage innovation while reducing its costs and risks. An approach to mitigate 
the risks and cost of innovation is to involve users in new product development (NPD) process [2] [3]. For instance, in a study conducted at $3 \mathrm{M}$, innovations from users were found to generate more sales than traditional market research techniques [4]. By involving users in NPD process, firms may benefit from lower development costs and enhanced user acceptance of the innovations [5]. To formalize this approach, user innovation communities (UICs) are increasingly being deployed by firms to manage users and source for their innovation ideas, for example, Starbucks, Dell Idea Storm, etc.

The main purpose of UIC creation is to obtain high-quality user-generated content. Enterprises not only guide users to generate content in the community, but also analyze and extract valuable knowledge from it. However, with the rapid development of the user's innovative community, the scale of community users continues to expand. Different users have great differences in their behaviors when participating in various activities in the community. Some has brought a lot of innovative knowledge, and some has spread the information of product, but there are also a large number of users of irrigation and diving, this part of the user's contribution to the community is minimal. Therefore, different participation behaviors of users will have different contribution values to enterprise in NPD process. Then, in this large number of users, to effectively classify these users based on the value of user contribution, a better understanding of user behaviors, roles and contributions in the NPD process is needed.

At present, most scholars focus on the influencing factors of user contribution in UICs, ignoring the measurement of user contribution value, and the source of research data is mostly based on questionnaires, which are subjective. Based on this, this paper takes the data of Huawei mobile phone community as the research object, obtains the actual user data from the community, and divides the user contribution value into two dimensions: user contribution content value and user interaction relationship value, based on the user's contribution value to the enterprise. The analysis results in six different user types that provide guidance for user management practices in UICs.

This paper is structured as follows. In the next section, we review the literature on user types and user contribution value in UICs. We then introduce the technical approaches used in this paper. In the following section, we give a brief overview of research setting and our method before we describe the results derived from our analysis. In the final section of the paper, we finish this paper by presenting the conclusions.

\section{Literature Review}

\subsection{User Types in UICs}

Previous studies provide important insights into the identification of different member roles in UICs. Early research of user classification in UICs is mostly qualitative from the perspective of user participation, such as Laverty and Corinne (1996) divided users into active, passive, inducer and manager [6]. Later and 
Zhan (2009) highlighted the important role that users' comments on the Internet (innovative communities or blogs) have on products [7]. Through text mining, he focused on exploring user attitudes, such as positive or negative attitudes. In recent years, more scholars have used quantitative methods to select the number of postings, attention numbers, page views and other indicators to classify users from the perspective of users' status in the community, user knowledge sharing behavior, or user publishing creative quality. Table 1 summarizes the classification and measurement indicators of users in UICs. As can be seen from Table 1, the current measurement of users in UICs seldom considers the factor of user contribution value, and some studies indicate that user contribution is an important factor in the success of UIC operation [8]. Therefore, it is necessary for us to explore from the perspective of user contribution value.

\subsection{User Contribution Value}

User contribution value refers to the ability to assess whether a user can help a company realize its benefits after purchasing a company's products or enjoying the company's services. There are not many scholars at home and abroad who have contributed value to the members of the user community. For example, Zhang M and Tang G Q (2016) proposed two situations of self-interest and altruism, and empirically verified that the self-interest and altruistic knowledge contribution would have a significant promotion to knowledge contribution behavior, and the influence of self-interested will is stronger than altruism [14]; Khansa and Ma et al. (2015) proposed a goal-oriented online community user participation model, taking the typical online Q\&A community Yahoo as an example. Through empirical analysis of online users' data, they proved the applicability of the model, it is found that membership, incentives and habits are the main factors affecting the active contribution behavior of online users [15]; Qin M and Qiao W et al. (2015) have defined online user behavior as two types in open innovation community: active contribution behavior and response contribution behavior. Based on the complex adaptive system theory, the empirical model of online user contribution behavior is established. Finally, the contribution behavior mechanism of online open innovation community users is analyzed [16].

Table 1. User classification.

\begin{tabular}{|c|c|c|}
\hline Researcher & Measurement Indicator & Classification \\
\hline Shen B, Hu Y F(2018) [9] & Forum points, registration days, posts & $\begin{array}{l}\text { Core users, active contributing users, passive contributing users, } \\
\text { social users, information acquisition users, silent users }\end{array}$ \\
\hline Guo W, Zheng Q (2017) [10] & $\begin{array}{l}\text { Creation Number, Population Degree, } \\
\text { Influence Degree }\end{array}$ & $\begin{array}{l}\text { Project leader, active designer, generalist, communicator, } \\
\text { passive designer, observer. }\end{array}$ \\
\hline Qi G J, Li Y Y (2016) [11] & $\begin{array}{l}\text { Ideas-submitted, Ideas-points, } \\
\text { Comments-submitted, Comments-received }\end{array}$ & $\begin{array}{l}\text { Core users, active social users, glamorous social users, active } \\
\text { and innovative users, effective innovative users, edge users }\end{array}$ \\
\hline Füller, et al. (2014) [12] & $\begin{array}{l}\text { Number of Ideas, Out-Degree Centrality, } \\
\text { In-Degree Centrality }\end{array}$ & $\begin{array}{l}\text { Socializer, Idea generator, Master, Efficient } \\
\text { contributor, Passive idea generator, Passive commentator }\end{array}$ \\
\hline Flore Barcellini, et al. (2014) [13] & $\begin{array}{l}\text { Access frequency, network relationship } \\
\text { structure }\end{array}$ & Interactors, information providers, coordinators, encouragers \\
\hline
\end{tabular}


Jeppesen and Laursen (2009) believed that knowledge contribution was provided by the users in UICs that were those with relevant knowledge. They focused on the value of leading users when sharing knowledge [17]. Frey and Lyuthje et al. (2011) explored the influence of knowledge level and participation motivation of online users on their contribution behavior in open innovation community, and found that external motivation is the most likely to make a non-substantive contribution to online users. The diversity of knowledge and internal motivation can improve the contribution of online users to enterprise innovation, and focused on the knowledge contribution level of innovative users [18].

From existing studies, we can find that there are relatively many empirical analysis and theoretical research on online users' contribution value. Most of them adopt the methods of questionnaire survey or simulation, and mainly focus on the identification and research of special users such as leading users and innovative users. There is still no discussion on the contribution value of other users. Therefore, this paper will analyze the contribution value of different roles in UICs established by enterprises

\section{Techniques and Measurements for User Analysis}

\subsection{Multiunit Methodologies}

The main methodologies used for identifying user roles in community include content analysis and SNA. Content analysis emphasizes user behaviors to the product. This method distinguishes user roles based on user action features, such as participation volume and frequency [10] [19], the type of interaction [20], decision-making power and technical capabilities [21], action forms [22], action temporal duration [23], user interests and inclination [24], as well as user actions at different stages of product innovation process [25]. SNA is a common method used in sociological research to distinguish positions and roles based on ties and relationships [26]. In user community analysis, SNA focuses on user statuses in user network and their interaction relationships [27]. The number of relationships, user involvement level, and user ties are the basis to distinguish user types [28]. During the NPD process in UICs, users improve the product together by submitting solutions, discussing ideas, and testing them. On the other hand, they communicate and build social relations. In this study, we stress that the quality of contributed ideas and the way how users communicate are with same importance. Content analysis and SNA are combined to identify the user roles. The content analysis is used to measure user efforts to the product innovation and the SNA is used to locate their position in the social network structured by users.

\subsection{User Characterizing Profiles}

The profiles are captured to describe a participant in terms of his/her behavior over time [22]. Content-related measurements (e.g., behavior, ideas number, and keywords) and relational measurements (e.g., centrality, in-degree, out-degree, 
and structure) are both needed in the complementary methods [12] [22]. In this study, we take creation number, knowledge degree, population degree, and influence degree as user behaviors measurements. The former two represent one's actions on product innovation and the latter two represent one's social property. By using these particular criteria, we could character user's efforts to the product and status in the user relation network. In order to evaluate how the users differ in contributions, we capture the contribution forms and contribution quality.

\section{Material and Methods}

\subsection{Research Setting}

Case study enables the researcher to investigate causes and relationships in greater details and over a longer period, as well as different viewpoints and explanations [29]. In this paper, the case study helps to analyze user roles and contributions with a large number of data from particular UIC and get an intuitive conclusion.

This study chooses a well-known UIC as the experimental object-Huawei cellphone forum in China, which is the only official interactive community for the users of Huawei cellphone. In communities, users and enthusiasts of the cellphone can freely communicate to make their ideas and propose strategies and methods for improvement of the cellphone. Also, it is a highly successful community. The community gathers over 20 million community members, collaborating on 100 million ideas. Therefore, we can collect enough data for research.

\subsection{Data Collection}

In Huawei cellphone forum, we have directly copied all the necessary data by web mining. Forum is a public community. The data we collect is open to all users and doesn't contain personal information. So there is no research ethics issue. The tool used for mining data is GooSeeker, a free plugin for Firefox browser. We can choose what to capture through rudimentary programming.

Through web mining, we copy more than 10064 participation records generated by about 6841 users, including creations and comments. From the data, we select users who contribute during the process or who communicate with others. Finally, 6832 users and their 9879 actions are used in this study.

\subsection{Measures of Contribution Behavior}

Creation Number (CreNum) measures what a user creates when participating in the product process. During the innovation process, users conduct various actions: "add/update an idea", "add/update a feedback", "add/update an instruction", and "add/update a test". One's CreNum is the sum of the four kinds of actions.

$$
\text { CreNum }=N_{\text {idea }}+N_{\text {feedback }}+N_{\text {instruction }}+N_{\text {test }}
$$

$$
N_{\text {idea }} \text { : the number of ideas; } N_{\text {feedback: }} \text { the number of feedbacks; } N_{\text {instruction }} \text { : the }
$$


number of instructions; $N_{\text {test }}$ : the number of tests.

Knowledge Degree (KnoDeg) measures how innovative the ideas of users are when participating in the product process. Research supports the assumption that creativity and innovation success is based not only on the quantity of contributed ideas but also quality on idea [12]. During the innovation process, the ability of users to understand product knowledge is different. Knowledge Degree refers to the sum of product key knowledge he/she owns. It is calculated using word segmentation technique.

$$
\mathrm{KnoDeg}=N_{\text {key word }}
$$

$N_{\text {key word: }}$ the number of key word in the ideas.

Out-degree Centrality (OutDeg) indicates the number of outgoing relationships of a node. It measures the number of direct comments that a user writes on the ideas of others or of direct replies to other comments. It captures how actively a user participates and engages in communication. It was calculated using UCINET 6

$$
\text { OutDeg }=\sum_{j}^{n-1} x_{i j}(i \neq j)
$$

If user $i$ builds relationships with $j$, then $x_{i j}=1$, otherwise $x_{i j}=0$.

In-degree Centrality (InDeg) captures the number of comments directed to a user, which was also calculated using UCINET 6. A participant who carries on many communicational relationships is considered to be prestigious [30]. Thus, the measure captures the ability of a user to be recognized by his or her peers for generating new, creative ideas, capturing attention, and arousing curiosity [13].

$$
\operatorname{InDeg}=\sum_{j}^{n-1} x_{i j}(i \neq j)
$$

If user $i$ receives relationships from $j$, then $x_{i j}=1$, otherwise $x_{i j}=0$.

\subsection{Data Analysis}

The data is analyzed to calculate the Creation Number and Knowledge Degree. In order to calculate the user's Knowledge Degree, this study uses the Chinese word segmentation system NLPIR to extract keywords from ideas published by users. The system fully considers the key factors such as word frequency, semantics, corpus and so on. At the same time, it combines the comprehensive judgment of part of speech to extract key words accurately. There are two main rules to extract keywords: 1). remove some meaningless words, such as "mobile phone", "Huawei", "P20", "PRO" and other similar words. 2) Statistics of the word frequency of each key word, select words whose frequency exceeds 5, and select 10807 keywords as high-frequency words. Some of the key words and their frequency are shown in Table 2. It shows that in Huawei cellphone forum, the key knowledge users are most concerned about is screen, photography and system, because they rank first. And it also shows that users discuss most of these topics. Then, the relationship matrix is created to describe the relation network 
Table 2. Key words and frequency statistics.

\begin{tabular}{cccccc}
\hline key Words & Frequency & Key Words & Frequency & Key Words & Frequency \\
\hline Screen & 303 & Video & 138 & Headset & 73 \\
Photograph & 256 & Update & 128 & Network & 73 \\
System & 235 & Software & 124 & Interface & 71 \\
Game & 214 & Battery & 105 & Discount & 70 \\
Setting & 192 & Power & 84 & Bug & 69 \\
Weixin & 178 & Camera & 83 & App & 66 \\
\hline
\end{tabular}

at each time period. Two users establish a relationship between them as soon as one comments the other. The row is the sources of relations, the column is the targets of relations and the crossover value represents the number of their communication. The UCINET 6 carries out the out-degree centrality and in-degree centrality of every user with the matrix imported in. User relationship network is depicted in Figure 1. It shows that the relationship is dense in the core of the network, while it is much sparser in the periphery. The result is in accordance with the core-periphery model [12]. This indicates that users differ considerably in the way they interact and participate, supporting our assumption of the existence of different user types.

Cluster analysis was applied to identify a typology of participants based on this set of our identified four measures. We operated the clustering procedure in the $\mathrm{R}$ software environment. According to previous studies, identified as the best stopping rules, cluster analysis supported a four-to-six-cluster solution [31]. According to the analysis of data results, a six-cluster solution was finally found to be the most meaningful and interpretable. The 6832 users were clustered into six groups according to four dimensions: CreNum, KnoDeg, OutDeg, and InDeg. The analysis results are provided in Table 3. Then, an ANOVA was used to test the differences among user roles on the four criteria. The F-value (see Table 3 ) indicates that the distinction is obvious and the clustering result is acceptable.

\section{Results}

According to the results of Table 3, six user roles are identified: passive contributor, socializer, core user, information acquiring user, active contributor, and diver.

Passive contributor acts as a personal role in NPD process. With total of 359 users and 5.3 percent, this user role shows ordinary features. When scanning its data, passive contributors learn knowledge of the product and their interested parts. They are also willing to submit their ideas and entries to their concerned problems. However, passive contributors seldom discuss their ideas with others. Consequently, they receive fewer responses than active contributors and their ideas are less popular.

Socializer acts as an interactive role in NPD process. Participants with this role (426 users and 6.2 percent) engage in the UICs very actively. Socializers interact 


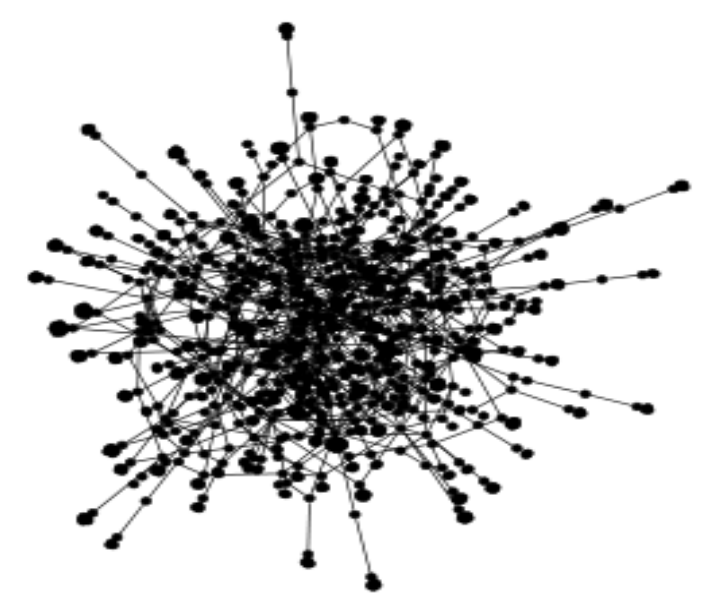

Figure 1. User relationship network.

Table 3. Cluster analysis results: six user roles.

\begin{tabular}{|c|c|c|c|c|c|c|c|c|}
\hline & Passive Contributor & Socializer & Core User & $\begin{array}{c}\text { Information } \\
\text { Acquiring User }\end{array}$ & $\begin{array}{c}\text { Active } \\
\text { Contributor }\end{array}$ & Diver & & \\
\hline & Mean & Mean & Mean & Mean & Mean & Mean & Total & F-value $(p)$ \\
\hline CreNum & 9.0 & 2.6 & 21.0 & 5.0 & 13.5 & 0.9 & & $569.54^{* * *}$ \\
\hline KnoDeg & 11.0 & 5.0 & 65.0 & 8.0 & 24.0 & 3.4 & & $574.30^{* * *}$ \\
\hline OutDeg & 2.7 & 97.1 & 53.0 & 2.0 & 15.5 & 2.4 & & $1835.02^{* * *}$ \\
\hline InDeg & 3.1 & 101.6 & 47.0 & 10.6 & 39.5 & 2.8 & & $1262.95^{* * *}$ \\
\hline $\begin{array}{l}\text { Number of } \\
\text { observations }\end{array}$ & 359 & 426 & 34 & 1982 & 157 & 3874 & 6832 & \\
\hline $\begin{array}{c}\text { Percent of } \\
\text { observations }\end{array}$ & 5.3 & 6.2 & 0.5 & 29 & 2.3 & 56.7 & 100 & \\
\hline
\end{tabular}

Notes: ${ }^{*} \mathrm{p}<0.05 ;{ }^{* *} \mathrm{p}<0.01 ;{ }^{* * *} \mathrm{p}<0.001$

with others in the process through comment, reply, and discussion. They have two obvious characteristics: 1) socializers generate a small number of creations, but are with high out-degree centrality and in-degree centrality. They join in the process to get relationship and friendship, so these users are more willing to communicate with others rather than submit their own originality. 2) The in-degree centrality is higher than out-degree centrality. This means they frequently get more response from others, while less comment on others' viewpoints.

Core user acts as a lead role in NPD process. This user role includes the smallest number of participants (only 34 members and less than 1 percent). However, this type of user contributes at an above-average rate on every one of the four criteria. Core users very actively engage in communication and interaction behavior within the network; unlike the socializer, this user type also provides a high volume of ideas, promising new breakthrough ideas. However, In contrast to other roles, these ideas attract a high level of attention among members. Furthermore, core users are very popular and influential within the communities. They often share information of the product and spread ideas and suggestions 
within the NPD process. The out-degree centrality is higher than in-degree centrality, which means that core users build more relationship and try to involve more users in the NPD process.

Information acquiring user acts as a useful role in NPD process. Compared to the previously described user types, the participants falling into this cluster seem to resemble the characteristics of an idea generator, although on a more moderate level. Again, the focus on contribution of an information acquiring user lies with idea-generating activities rather than with active commenting behavior. However, compared to passive contributors and in relation to the number of submitted ideas, the information acquiring user is able to attract attention among UICs members more "efficiently." Hence, with fewer submitted ideas, this user type is able to attract the same level of attention as the passive contributor with a very high number of submitted designs.

Active contributor acts as multiple boundaries role in NPD process. They generate a certain number of ideas and entries and are helpful to push the innovation. Besides, active contributors are much more popular than passive contributors because of not only their great ideas and suggestions but also their willingness to communicate with others. In the process of communication, they show an interactive role. This user role interests and performs widely and actives at every aspect of the NPD process. Though being a small cluster (157 users and $2.3 \%$ ), active contributors keep high out-degree centrality and in-degree centrality.

Diver takes place $56.7 \%$ of the users in the UICs, more than other user roles. They seldom engage in NPD process, neither offering new ideas and entries nor communicating with others continuously. Compared with the previous user roles, they don't show persistent enthusiasm and are more likely bystanders or onlookers.

\section{Discussion}

\subsection{Theoretical Implications}

In this study, content analysis, SNA, and cluster method are employed to investigate user roles and contributions during the NPD process in UICs. User roles are identified as passive contributor, socializer, core user, information acquiring user, active contributor, and diver. These user roles are consistent with the roles in traditional NPD within firms, performing the characteristic of a lead role, interactive role, multiple boundaries role, and personal role [32]. However, they show obvious differences. First, users are free to participate in and leave off the community and they could do whatever they like in the process without any restriction (rule, law, and limitations), which are not found in NPD process within traditional firms. Second, only a small number of key users (core user, active contributor, passive contributor, and Information acquiring user) are contributive enough to the innovation process. This is different from the situation within firms that most members are contributive. Third, a large number of users act as 
Divers, which are not found in NPD process within firms. Therefore, user roles, in the condition of freedom and openness, are different from the roles identified in collaborative innovation within firms.

Some previous studies on online communities also categorized some user types, such as lurkers and posters [33], active individuals and outsiders [24], master and efficient contributor [12], core team and committer [20]. However, roles and contributions of these users are confused. This study analyses user roles and contributions in the NPD process. Core users, who organize and control the NPD process, are clearer on responsibilities and contributions than "active contributor". Active contributors generate design solutions and fulfill user demands than passive contributors. They are more appropriate roles to NPD process than passive contributors and Information acquiring. Similarly, the other user roles identified in this study are also proper to the NPD process in UICs.

\subsection{Managerial Implications}

The research proposed in this paper offers epistemic contributions dealing with roles and contributions of participants in the NPD process in UICs. In addition, we should pay attention to another important question: How to make user participation convenient and keep their continuity during the process? Users engage in the process in various ways and for peculiar value as explained above. In order to keep users' enthusiasm, why and how they participate should be considered. In UICs, users engage voluntarily for assorted reasons: learning, monetary rewards, intrinsic enjoyment, knowledge diversity, product improvement, and prestige [34]. In this study, the NPD process is joined under user voluntariness, and the innovation and advance of the product are the main reason why users get together. So it's important to keep the product improving. Some studies have pointed out that users are more willing to engage in the tasks with economic returns. Therefore, the community practitioners should establish a compensation system to evaluate and record user contribution for the long term process, and then distribute some revenue of the product to the most important contributors. For the users who want to get relationships, a perfect communication platform and methods should be provided. For users who want to learn knowledge, previous knowledge created by users should be accumulated and retained so that users could get access to it. In conclusion, users, who are also creators, witnesses, and customers of the product, should be closely associated to the product with effective methods to make the product success.

\section{Limitations and Further Research}

Certainly, this paper has some limitations and raises questions calling for further research. As this paper was exploratory in nature, the question of generalizability arises. However, we are confident that the results of our study can be generalized to user roles and contributions in UICs like Huawei cellphone forum for two reasons. First, we found the same basic social structure (e.g., dense, active core 
and large, passive periphery, heterogeneity regarding quality and quantity of contributions) as in other UICs described in our literature review. Hence, we believe that these basic social structures are stable across contexts. Second, the Huawei cellphone forum is quite representative for many other UICs with highly active. Nevertheless, while the basic social structure does not vary across different types of communities, specific behavioral patterns, size of the user clusters, and so forth might be influenced by the specific context of a community (e.g., duration, incentives, and topic). Therefore, the generalizability of identified user types and its sensitivity to contextual factors still needs to be tested.

It is worthwhile to further explore whether the roles of users in the UICs will change over time while the goal of this paper was not to explain the evolution and dynamics of user roles. Because that would allow for the creation of strategies to transform users from one type to another (e.g., active contributors to core users).

Finally, the user measurement index selected in this paper does not take into account the user's personal attributes, such as age, gender, location, cultural level, etc. In the UIC, these personal attributes may have an important impact on the product knowledge, interaction and expression ability they master, thus affecting the user classification results. Therefore, we hope that our study inspires other researchers to further explore the emerging topic of UICs and gain a better understanding of the roles and contributions of users.

\section{Conclusions}

In this study, we analyzed user behaviors and investigated user roles and contributions during the NPD process in the UICs. User action data is obtained through web mining from Huawei cellphone forum. With the methodologies including social network analysis, cluster and content analysis, user roles are identified as: passive contributor, socializer, core user, information acquiring user, active contributor, and diver. After analyzing user relations and contributions, we find that: 1) the collaboration innovation team has a similar structure as core-periphery model that has been concluded in other user communities. This model seems more noticeable because a large number of users without professional innovation ability can hardly make a material contribution in technical NPD process. 2) Core users play an important role in proposing the most diverse solutions, which requires them to have professional knowledge. 3) Users with strong ability or good relationship submit the best solutions and then optimize them by discussing with public users. 4) Users achieve value through their voluntary participation way, such as relationship, credibility, status, achievement, economic returns, knowledge and information. Our findings also lead to several managerial implications for community practitioners.

This study contributes to both academic research and practical guidance on NPD in UICs, and has the following potential application: First, the methods employed in this study could be used to identify user roles in other UICs. The 
multiunit methodologies combine content analysis and SNA to give a holistic profile of user behaviors. Second, the results of the study could help researchers and practitioners get a deep understanding of user behaviors, roles, and contributions. Third, the findings and insights could help practitioners grasping user value. Finally, the managerial implication could be used to improve users' convenience and enthusiasm of participation.

\section{Conflicts of Interest}

The authors declare no conflicts of interest regarding the publication of this paper.

\section{References}

[1] Timko, O. and Dong, J.Q. (2017) Stimulating Innovation by User Feedback on Social Media: The Case of an Online User Innovation Community. Technological Forecasting \& Social Change, 7, 10-17.

[2] Von Hippel, E. (2009) Democratizing Innovation: The Evolving Phenomenon of User Innovation. International Journal of Innovation Science, 1, 29-40. https://doi.org/10.1260/175722209787951224

[3] Zwass, V. (2010) Co-Creation: Toward a Taxonomy and an Integrated Research Perspective. International Journal of Electronic Commerce, 15, 11-48. https://doi.org/10.2753/JEC1086-4415150101

[4] Lilien, G.L., Morrison, P.D., Searls, K., Sonnack, M. and von Hippel, E. (2002) Performance Assessment of the Lead User Idea-Generation Process for New Product Development. Management Science, 48, 1042-1059. https://doi.org/10.1287/mnsc.48.8.1042.171

[5] Von Hippel, E. (2005) Democratizing Innovation. MIT Press, Cambridge. https://doi.org/10.7551/mitpress/2333.001.0001

[6] Laverty, C.Y.C. (1996) Internet Primer: Workshop Design and Objectives. Internet Reference Services Quarterly, 1, 35-53. https://doi.org/10.1300/J136v01n03_05

[7] Zhan, J., Loh, H.T. and Liu, Y. (2009) Gather Customer Concerns from Online Product Reviews-A Text Summarization Approach. Expert Systems with Applications, 36, 2107-2115. https://doi.org/10.1016/j.eswa.2007.12.039

[8] Fara, J.S., Jarvenpaa, S. and Majchzak, A. (2011) Knowledge Collaboration in Online Communities. Organization Science, 22, 1224-1239. https://doi.org/10.1287/orsc. 1100.0614

[9] Shen, B. and Hu, Y.F. (2018) Research on User Classification of Virtual Brand Community Based on User Behavior Characteristics. Information Exploration, 7, $12-18$.

[10] Guo, W., Zheng, Q. and An, W.J. (2017) User Roles and Contributions during the New Product Development Process in Collaborative Innovation Communities. Applied Ergonomics, 63, 106-114. https://doi.org/10.1016/j.apergo.2017.04.013

[11] Qi, G.J. and Li, Y.Y. (2016) Research on the Contribution Degree of Online Users in Enterprise Open Innovation Community. Scientific and Technological Progress and Countermeasures, 33, 81-87.

[12] Füller, J., Hutter, K., Hautz, J., et al. (2014) User Roles and Contributions in Innovation-Contest Communities. Journal of Management Information Systems, 31, 273-307. https://doi.org/10.2753/MIS0742-1222310111 
[13] Flore, B., Françoise, D. and Burkhardt, J.M. (2014) A Situated Approach of Roles and Participation in Open Source Software Communities. Human-Computer Interaction, 29, 205-255. https://doi.org/10.1080/07370024.2013.812409

[14] Zhang, M., Tang, G.Q. and Zhang, L. (2016) Research on the Influencing Factors of User Knowledge Contribution Behavior in Online Social Learning. Information Journal, 35, 146-152.

[15] Khansa, L., Ma, X. and Liginlal, D. (2015) Understanding Members' Active Participation in Online Question-and-Answer Communities: A Theory and Empirical Analysis. Journal of Management Information Systems, 32, 162-203. https://doi.org/10.1080/07421222.2015.1063293

[16] Qin, M., Qiao, H. and Chen, L.H. (2015) Research on the Contribution Behavior of Online Users in Enterprise Open Innovation Community Based on CAS Theory: A Case Study of Domestic Well-Known Enterprise Community. Management Review, 27, 126-137.

[17] Jeppesen, L.B. and Laursen, K. (2009) The Role of Lead Users in Knowledge Sharing. Research Policy, 38, 1582-1589. https://doi.org/10.1016/j.respol.2009.09.002

[18] Frey, K., Lüthje, C. and Haag, S. (2011) Whom Should Firms Attract to Open Innovation Platforms? The Role of Knowledge Diversity and Motivation. Long Range Planning, 44, 397-420. https://doi.org/10.1016/j.lrp.2011.09.006

[19] Wang, L., Ma, L.J., Peng, W., Zheng, Q., Guo, W., et al. (2018) Innovation Community User Innovation Ability Analysis. Science and Technology Progress and Policy, 9, 42-47.

[20] Hedberg, H. and Iivari, N. (2009) Integrating HCI Specialists into Open Source Software Development Projects. IFIP International Conference on Open Source Systems, Skövde, 3-6 June 2009, 251-263. https://doi.org/10.1007/978-3-642-02032-2_22

[21] Bach, P.M. and Twidale, M. (2010) Social Participation in Open Source: What It Means for Designers. Interaction, 17, 70-74. https://doi.org/10.1145/1744161.1744177

[22] Barcellini, F., Prost, L. and Cerf, M. (2015) Designers' and Users' Roles in Participatory Design: What Is Actually Co-Designed by Participants? Applied Ergonomics, 50, 31-40. https://doi.org/10.1016/j.apergo.2015.02.005

[23] Bayus, B.L. (2013) Crowdsourcing New Product Ideas over Time: An Analysis of the Dell IdeaStorm Community. Management Science, 59, 226-244. https://doi.org/10.1287/mnsc.1120.1599

[24] Arazy, O. and Nov, O. (2010) Determinants of Wikipedia Quality: The Roles of Global and Local Contribution Inequality. The 2010 ACM Conference on Computer Supported Cooperative Work, Savannah, 6-10 February 2010, 233-236. https://doi.org/10.1145/1718918.1718963

[25] Romero, D. and Molina, A. (2011) Collaborative Networked Organisations and Customer Communities: Value Co-Creation and Co-Innovation in the Networking Era. Production Planning Control, 22, 447-472. https://doi.org/10.1080/09537287.2010.536619

[26] Borgatti, S.P., Mehra, A., Brass, D.J. and Labianca, G. (2009) Network Analysis in the Social Sciences. Science, 323, 892-895. https://doi.org/10.1126/science.1165821

[27] Fuge, M., Tee, K., Agogino, A. and Maton, N. (2014) Analysis of Collaborative Design Networks: A Case Study of Open Ideo. Computer Information Science, 14, 21-39. https://doi.org/10.1115/1.4026510

[28] Toral, S.L., Martínez-Torres, M.R. and Barrero, F. (2010) Analysis of Virtual Com- 
munities Supporting OSS Projects Using Social Network Analysis. Information Software Technology, 52, 296-303. https://doi.org/10.1016/j.infsof.2009.10.007

[29] Eisenhardt, K.M. (1989) Building Theories from Case Study Research. Academic Management Review, 14, 532-550. https://doi.org/10.5465/amr.1989.4308385

[30] Faust, K. and Wasserman, S. (1992) Centrality and Prestige: A Review and Synthesis. Journal of Quantitative Anthropology, 4, 23-78.

[31] Milligan, G.W. and Cooper, C. (1985) An Examination of Procedures for Determining the Number of Clusters in a Data Set. Psychometrica, 50, 159-179. https://doi.org/10.1007/BF02294245

[32] Sonnenwald, D.H. (1996) Communication Roles That Support Collaboration during the Design Process. Design Studies, 17, 277-301. https://doi.org/10.1016/0142-694X(96)00002-6

[33] Füller, J., Jawecki, G. and Mühlbacher, H. (2007) Innovation Creation by Online Basketball Communities. Business Research, 60, 60-71. https://doi.org/10.1016/j.jbusres.2006.09.019

[34] Füller, J. (2010) Refining Virtual Co-Creation from a Consumer Perspective. California Management Review, 52, 98-122. https://doi.org/10.1525/cmr.2010.52.2.98 